\title{
Inversion of Elastic Impedance for Unconsolidated Sediments
}

Scientific Investigations Report 2006-5081 


\section{Inversion of Elastic Impedance for Unconsolidated Sediments}

By Myung W. Lee

Scientific Investigations Report 2006-5081 


\section{U.S. Department of the Interior DIRK KEMPTHORNE, Secretary \\ U.S. Geological Survey \\ P. Patrick Leahy, Acting Director}

\section{U.S. Geological Survey, Reston, Virginia: 2006}

Posted online July 2006

Version 1.0

This publication is only available online at http://www.usgs.gov/sir/2006/5081/

For more information on the USGS - the Federal source for science about the Earth, its natural and living resources, natural hazards, and the environment:

World Wide Web: http://www.usgs.gov

Telephone: 1-888-ASK-USGS

Any use of trade, product, or firm names is for descriptive purposes only and does not imply endorsement by the U.S. Government.

Although this report is in the public domain, permission must be secured from the individual copyright owners to reproduce any copyrighted materials contained within this report.

Suggested citation:

Lee, M.W., 2006, Inversion of elastic impedance for unconsolidated sediments: U.S. Geological Survey Scientific Investigations Report 2006-5081, 14 p. 


\section{Contents}

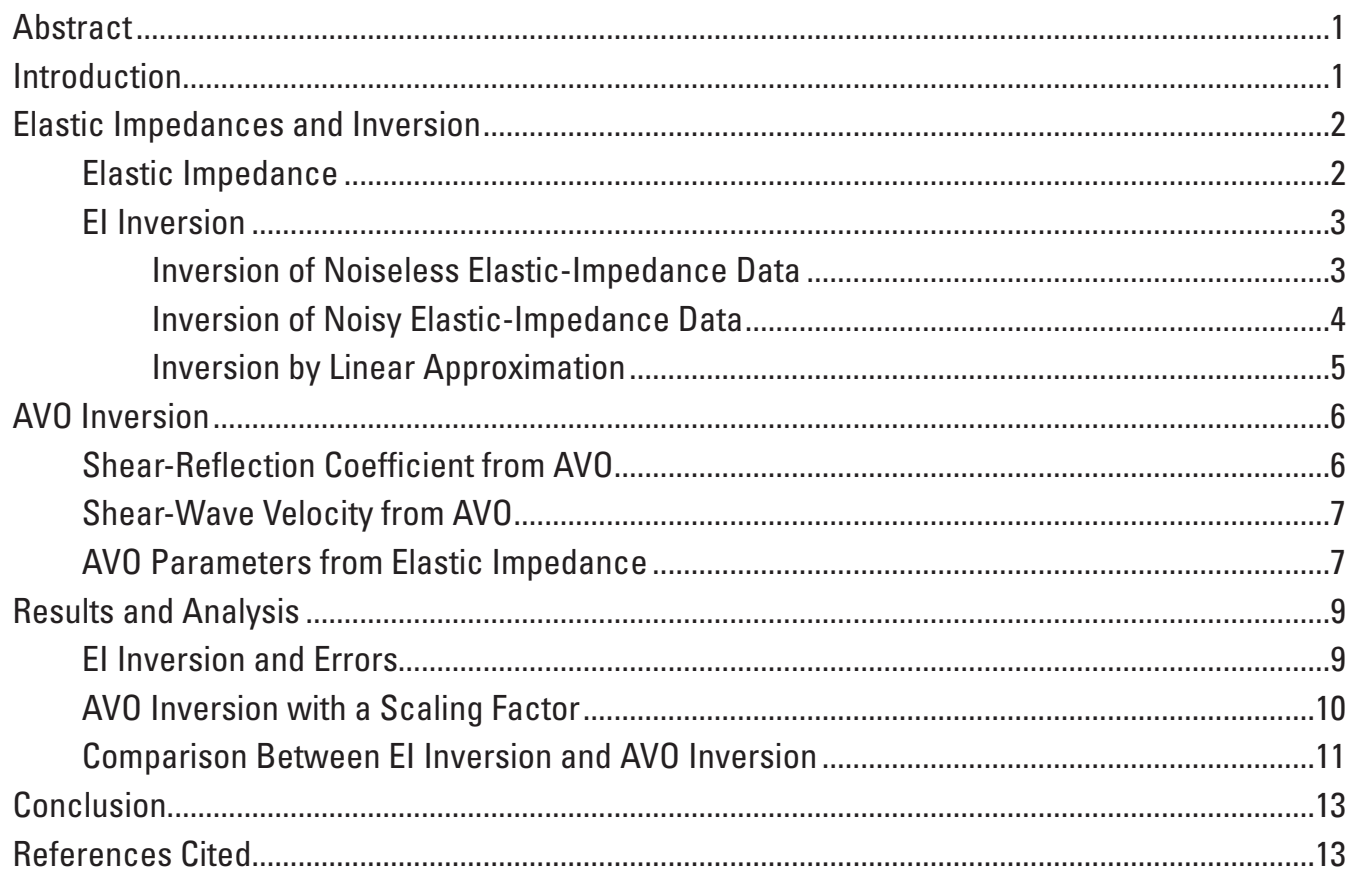

\section{Figures}

1-11. Graphs showing:

1. Examples of elastic impedance calculated from well logs at IPAD I-16 well

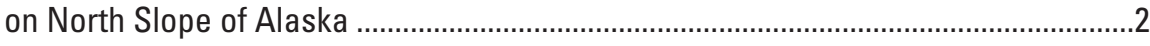

2. Examples of elastic-impedance inversion using noise-free data ...............................4

3. Example of elastic-impedance inversion for P-wave and density using noisy El data

4. S-wave velocities that resulted from elastic-impedance inversion of noisy

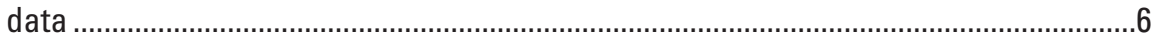

5. Relationship between reflection coefficient and squared ratio of S-wave velocity to $\mathrm{P}$-wave velocity.

6. Estimated shear-reflection coefficient at IPAD I-16 well on North Slope of Alaska

7. Estimated S-wave velocities from amplitude-versus-offset inversion........................

8. Errors introduced into $\mathrm{S}$-wave velocities due to error in elastic impedance ...........10

9. S-wave velocities resulting from elastic-impedance inversions for various noisy elastic impedances.

10. S-wave velocities estimated from various inversion methods by using angle stack with 10 percent noise

11. A comparison between shear-wave velocity estimated from elastic-impedance inversion by using exact formula and shear-wave velocity estimated from linear approximation 


\section{Conversion Factors}

\begin{tabular}{lcl}
\hline \multicolumn{1}{c}{ Multiply } & By & \multicolumn{1}{c}{ To obtain } \\
\hline meter $(\mathrm{m})$ & Length & \\
kilometer $(\mathrm{km})$ & 3.281 & foot $(\mathrm{ft})$ \\
& 0.6214 & mile $(\mathrm{mi})$ \\
\hline gram per cubic centimeter $\left(\mathrm{g} / \mathrm{cm}^{3}\right)$ & Density & \\
\hline
\end{tabular}

\begin{tabular}{lcl}
\hline \multicolumn{1}{c}{ Multiply } & By & \multicolumn{1}{c}{ To obtain } \\
\hline foot $(\mathrm{ft})$ & Length & \\
mile $(\mathrm{m})$ & 0.3048 & meter $(\mathrm{m})$ \\
& 1.609 & kilometer $(\mathrm{km})$ \\
\hline pound per cubic foot $\left(\mathrm{lb} / \mathrm{ft}^{3}\right)$ & Density & \\
\hline
\end{tabular}




\title{
Inversion of Elastic Impedance for Unconsolidated Sediments
}

\author{
By Myung W. Lee
}

\section{Abstract}

The presence of gas hydrate in pore spaces of unconsolidated sediments increases both $\mathrm{P}$-wave and $\mathrm{S}$-wave velocities, whereas in sediments that are partially gas saturated, P-wave velocities decrease significantly and the $\mathrm{S}$-wave velocities either increase slightly or do not change. Also, shallow sediments inside the gas-hydrate stability zone are commonly overpressured, in which case both $\mathrm{P}$ - and $\mathrm{S}$-wave velocities decrease as pore pressure increases. Therefore, elastic properties of gas-hydrate-bearing sediments are important for quantifying amounts of gas hydrate as well as for discriminating its effect on velocity from the effect of free gas or pore pressure. Elastic properties of gas-hydrate-bearing sediments can be estimated from angle stacks by using elastic inversion methods. Commonly used elastic inversion methods assume that the $V_{S} / V_{P}$ ratio is 0.5 . However, the $V_{S} / V_{P}$ ratios of gashydrate-bearing sediments are generally much less than 0.5 , unless the gas-hydrate saturation is high (more than about 80 percent). The $V_{S} / V_{P}$ ratio of 0.5 (or some other constant) is assumed, because the elastic inversion requires the $V_{S} / V_{P}$ ratio to be known. In order to perform elastic inversion for sediments whose $V_{S} / V_{P}$ ratio is much less than 0.5 , predicted $\mathrm{S}$-wave velocities are used to derive the $V_{S} / V_{P}$ ratio necessary for the inversion. Model results indicate that this approach works well for both noise-free and noisy data. However, for inverting inaccurate data (that is, data containing random noise), a sequential estimation of $\mathrm{P}$-wave impedance from the zero-offset stack and then S-wave impedance from the faroffset stack provides reliable $\mathrm{P}$ - and $\mathrm{S}$-wave velocities.

\section{Introduction}

Identification and quantification of gas hydrate present in sediments are important research areas (Collett, 2002), and detailed seismic analysis is necessary to detect gas-hydratebearing sediments. The effect of gas hydrate in sediments manifests itself in changes in seismic amplitude and traveltime. Because seismically driven interval velocities of sediments with and without gas hydrate differ, gas-hydrate-bearing sediments can be identified and the amount of gas hydrate can be quantified (for example, see Tinivella and Lodolo, 2000; Lu and McMechan, 2002; Jin and others, 2003).

Detailed seismic velocity information for sediments is essential to accurately estimate the amount of gas hydrate. Arrival times provide the low-frequency velocity information, and amplitudes provide the high-frequency velocity information. By combining amplitude information with traveltime information, detailed interval velocities can be estimated. The high-frequency part of the velocity information can be deduced from the amplitude-versus-offset (AVO) intercept, and gradient or elastic impedances calculated through angle stacks.

Elastic impedance (EI) is a generalization of acoustic impedance (AI) using a three-term approximation of reflection coefficients (Connolly, 1999). AI has been used successfully to derive P-wave velocities for gas-hydrate-bearing sediments (Sakai, 1999; Lu and McMechan, 2002; Jin and others, 2003). However, more detailed seismic-attribute analysis for gashydrate-bearing sediments can be accomplished by estimating $\mathrm{S}$-wave velocities from the seismic data using elastic inversion (Mallick and others, 2000; Lu and McMechan, 2002).

EI can be calculated different ways-for example, by full prestack inversion (Mallick, 1999), poststack inversion using AVO (termed "AVO inversion"), and poststack inversion using elastic impedance (termed "EI inversion"). Although computationally expensive, the full prestack inversion is the optimum approach to obtain elastic parameters from seismic data. However, many good results are obtained by using AVO inversion (Mallick, 2001) or EI inversion (Lu and McMechan, 2004).

AVO inversion or EI inversion generally assumes that $V_{S} / V_{P}=0.5$ or another constant value (Connolly, 1999; Mallick and others, 2000; Mallick, 2001), but Lu and McMechan (2004) used a variable $V_{S} / V_{P}$ ratio on the basis of empirical approximation. It has been shown that the error due to the assumption of $V_{S} / V_{P}=0.5$ in the AVO inversion can be easily corrected; however, no simple correction exists for the EI inversion, and the estimated $\mathrm{S}$-wave velocity is sensitive to $V_{S} / V_{P}$ (Mallick, 2001).

In this report, the behaviors of EI and AVO inversions using well logs acquired at the IPAD I-16 well on the North Slope of Alaska are investigated through assumptions of varying $V_{S} / V_{P}$. 


\section{Elastic Impedances and Inversion}

One of the primary goals of seismic-data processing is estimating elastic parameters-that is, $\mathrm{P}$-wave velocity $\left(V_{p}\right)$, $\mathrm{S}$-wave velocity $\left(V_{S}\right)$, and density $(\rho)$ - from seismic data. Mallick (1999) demonstrated that the prestack genetic algorithm inversion provides accurate $\mathrm{P}$ - and $\mathrm{S}$-wave impedances. In the absence of borehole information, an efficient algorithm is developed through the use of a combination of prestack and poststack inversion (hybrid seismic inversion according to Mallick and others, 2000). Hybrid inversion methodology uses the prestack inversion algorithm at discrete locations in combination with AVO analysis or elastic impedances.

Elastic parameters also can be obtained from angle stacks and AVO analysis. Lu and McMechan (2004) derived elastic parameters directly from angle stacks by using the concept of elastic impedance (Connolly, 1999). AVO intercept and gradient also can be used (Mallick and others, 2000). Details of EI and AVO inversions are presented in this report.

\section{Elastic Impedance}

Impedance is generally defined as a product of P-wave velocity and density and is related to a normal-incidence reflection seismogram. However, this definition cannot be applied to far-offset data. In order to generalize the normal-incidence impedance concept, Connolly (1999) defined EI as follows:

$$
E I(\theta)=V_{P}^{\left(1+\tan ^{2} \theta\right)} V_{S}^{-8 k \sin ^{2} \theta} \rho^{\left(1-4 k \sin ^{2} \theta\right)}
$$

where $k=\left(V_{s} / V_{P}\right)^{2}$ and $V_{P}, V_{s}, \rho$, and $\theta$ are P-wave velocity, $\mathrm{S}$-wave velocity, density, and angle of incidence, respectively. The dimensionality of EI depends on the angle of incidence. In order to remove the variable dimensionality from EI, Whitcombe (2002) introduced a normalized EI, which is defined as

$$
\begin{gathered}
E I(\theta)=V_{P_{0}} \rho_{0}\left[\left(V_{P} / V_{P_{0}}\right)^{\left(1+\tan ^{2} \theta\right)}\right. \\
\left.\left(V_{S} / V_{S_{0}}\right)^{-8 k \sin ^{2} \theta}\left(\rho / \rho_{0}\right)^{\left(1-4 k \sin ^{2} \theta\right)}\right]
\end{gathered}
$$

where $V_{P_{0}}, V_{S_{0}}$, and $\rho_{0}$ are constants. These constants can have real meaning such as the average velocities and densities in a given area. However, to make the dimensionality of EI constant, $V_{P_{0}}, V_{S_{0}}$, and $\rho_{0}$ can be arbitrarily set; the approach used in this report was to set these constants arbitrarily to one.

Figure $1 A$ shows calculated EIs at the IPAD I-16 well on the North Slope of Alaska for three difference angles of incidence: $0^{\circ}$ (vertical incidence, denoted by $\mathrm{EI}(0)$ ), $15^{\circ}$, and $30^{\circ}$. $\mathrm{EI}(15)$ is similar to acoustic impedance (AI), but $\mathrm{EI}(30)$ is much higher than AI. According to Connolly (1999), the magnitude of EI decreases as the angle of incidence increases. Modeling for a low-porosity consolidated rock shows that EI decreases as the angle of incidence increases, as Connolly
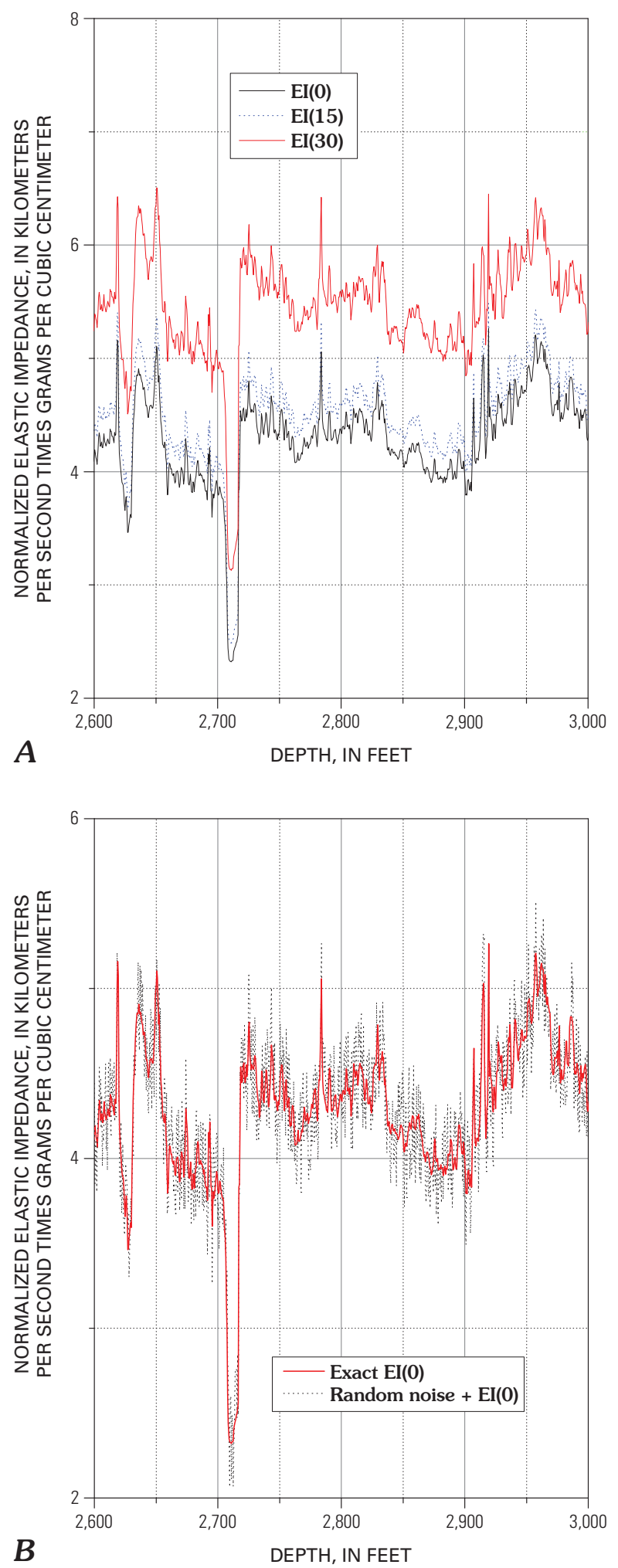

Figure 1. Examples of elastic impedance (EI) calculated from well logs at the IPAD I-16 well on the North Slope of Alaska. $A$, Noise-free Els calculated at $\theta=0^{\circ}, 15^{\circ}$, and $30^{\circ}$. $B$, Noisy $\mathrm{El}(0)$ generated by adding 1 percent random noise to $\mathrm{El}(0)$ in $A$. 
(1999) indicated. However, the behavior of EI presented in figure 1 is different from the general behavior of EI observed by Connolly. The increase of EI with increasing angle of incidence is due to the unconsolidated nature of the sediments at the IPAD I-16 well.

The reflectivity of normal incidence $R_{0}(t)$, which is approximately equal to zero-offset stack, can be approximated by

$$
R_{0}(t)=\frac{1}{2} \frac{d \ln (A I)}{d t}
$$

where $\mathrm{AI}$ is acoustic impedance or $\mathrm{EI}(0)$ and $t=$ two-way traveltime. Note that the EI defined in equation $1 \mathrm{~b}$ has the same dimensionality as AI. AI can be derived from the normal-incidence reflectivity section by

$$
\ln (A I)=\int 2 R_{0}(t) d t
$$

By using a similar approach as that for AI, Connolly (1999) derived the EI from the reflection coefficient at the angle of incidence $\theta, R_{\theta}(t)$, which is approximately equal to angle stacks at $\theta$, as follows:

$$
R_{\theta}(t)=\frac{1}{2} \frac{d \ln (E I(\theta))}{d t}
$$

and

$$
\ln (E I(\theta))=\int 2 R_{\theta}(t) d t
$$

As shown in equation 3, EI can be estimated from the angle stack. However, the low-frequency part of EI should be provided to derive reasonable impedance from equation 3. Mallick and others (2000) demonstrated that the prestack genetic algorithm inversion delivers the accurate low-frequency $\mathrm{P}$ - and S-wave impedances necessary for equation 3.

\section{El Inversion}

Equation 1 can be written as

$$
\begin{gathered}
\ln (E I(\theta))=\left(1+\tan ^{2} \theta\right) \ln \left(V_{P}\right)+ \\
\left(-8 k \sin ^{2} \theta\right) \ln \left(V_{S}\right)+\left(1-4 k \sin ^{2} \theta\right) \ln (\rho)
\end{gathered}
$$

The unknowns in equation 4 are $V_{P}, V_{S}$, and $\rho$. Therefore, if three EIs at different angles are known, these unknowns can be calculated by solving the following matrix equation:

$$
\left[\begin{array}{l}
1+\tan ^{2} \theta_{1}-8 k \sin ^{2} \theta_{1} 1-4 k \sin ^{2} \theta_{1} \\
1+\tan ^{2} \theta_{2}-8 k \sin ^{2} \theta_{2} 1-4 k \sin ^{2} \theta_{2} \\
1+\tan ^{2} \theta_{3}-8 k \sin ^{2} \theta_{3} 1-4 k \sin ^{2} \theta_{3}
\end{array}\right]\left[\begin{array}{l}
\ln \left(V_{P}\right) \\
\ln \left(V_{S}\right) \\
\ln (\rho)
\end{array}\right]=\left[\begin{array}{l}
\ln \left(E I\left(\theta_{1}\right)\right) \\
\ln \left(E I\left(\theta_{2}\right)\right) \\
\ln \left(E I\left(\theta_{3}\right)\right)
\end{array}\right]
$$

\section{Inversion of Noiseless Elastic-Impedance Data}

One problem in solving equation 5 is the unknown $k$. It is common to use $k=0.25$, which is the case of $V_{S} / V_{P}=0.5$. However, it is noted that values for $k$ as low as 0.1 have been used for unconsolidated sediments (Lu and McMechan, 2004) and can be much lower. The strategy of solving equation 5 is as follows:

1. Start with $k$ (initial $k$ is $k_{i n t}$ ).

2. Set $k_{\text {old }}=k$.

3. Solve equation 5 , and calculate $k_{\text {new }}$ with the inversion result.

4. Compare $k_{\text {old }}$ with $k_{\text {new }}$, and if the difference is less than the critical value, stop; if not, proceed to step 5 .

5. Set $k=\left(k_{\text {old }}+k_{\text {new }}\right) / 2$, or choose a new $k$ by other means.

\section{Go to step 2 .}

Figure 2 shows inversion results using this procedure. The P-wave velocity (fig. $2 A$ ) and density (fig. $2 C$ ) are accurately estimated from the inversion of noiseless EI shown in figure $1 A$. However, the inverted $\mathrm{S}$-wave velocities (fig. $2 B$ ) are inaccurate in some places. The inversion shows that if the correct $k$ is used, the inversion is exact.

In order to overcome the problem of a possibly incorrect $k$, the following procedure is tested:

1. Calculate porosity by using the estimated density from the inversion result for noiseless EI.

2. Predict S-wave velocity from the previously inverted $\mathrm{P}$-wave velocity and calculated porosity (for example, Lee, 2005) or from just the porosity (for example, Lee, 2002).

3. Calculate $k$ from the previously inverted $\mathrm{P}$-wave velocity and predicted $\mathrm{S}$-wave velocity.

4. Solve equation 5 with this new $k$.

The results of the new inversion procedure are shown as the solid red line in figure $2 B$ (note the significant improvement of the $\mathrm{S}$-wave velocity through the use of the new procedure). The mismatch near 2,700 ft is due to the use of the wrong lithology in the inversion (this interval corresponds to a coal seam). Because shaly sandstone lithology is used, the predicted S-wave velocity is higher than the measured velocity. Consequently, the inverted S-wave velocity is higher than the measured velocity.

This inversion procedure using equation 5 is not practical for noisy data, as was noted by Mallick and others (2000) and Lu and McMechan (2004). However, this inversion exercise indicates the importance of applying a reasonable value for $k$; instead of merely assuming that $k=0.25$, for example, the predicted S-wave velocity may be used to compute $k$ in the inversion scheme. 

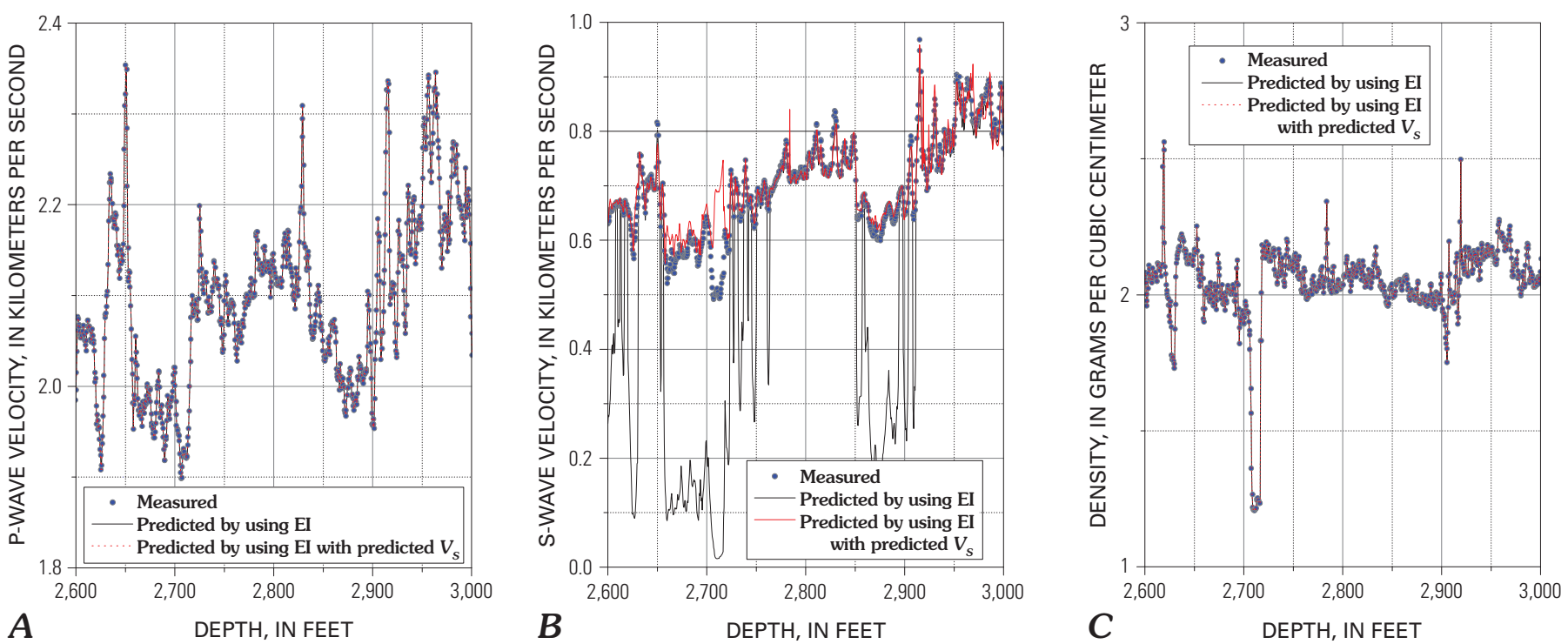

Figure 2. Examples of elastic-impedance (El) inversion using noise-free data shown in figure $1 A$. The black lines denote the Elinversion result without using predicted S-wave velocity $\left(V_{S}\right)$. Red lines represent the El-inversion result using the predicted S-wave velocity during inversion.

\section{Inversion of Noisy Elastic-Impedance Data}

As mentioned previously, the inversion scheme shown in equation 5 is unstable even with small amounts of random noise, so is not practical for real seismic data inversion. In order to overcome this problem, the following inversion procedure is attempted, following $\mathrm{Lu}$ and McMechan (2004).

1. Estimate the P-wave impedance (AI inversion) by using $\mathrm{EI}(0)$ or AI.

2. Calculate P-wave velocity and density from the estimated $\mathrm{P}$-wave impedance at step 1 by using the relationship between P-wave velocity and density such as that given by Gardner and others (1974).

3. Calculate porosity from density.

4. Predict $\mathrm{S}$-wave velocity from the previously inverted P-wave velocity (at step 2 ) and calculated porosity (at step 3) (for example, Lee, 2005).

5. Calculate $k$ from the previously inverted P-wave velocity and predicted $\mathrm{S}$-wave velocity. For noisy data, smoothing the calculated $k$ is recommended.

6. Solve the following equation for $V_{S}$ by using EI calculated at $\theta \approx 30^{\circ}$ :

$\ln \left(V_{S}\right)=\frac{\left(1+\tan ^{2} \theta\right) \ln \left(V_{P}\right)-\ln (E I(\theta))+\left(1-4 k \sin ^{2} \theta\right) \ln (\rho)}{8 k \sin ^{2} \theta}$
Figure $1 B$ shows an example of noisy impedance $(\operatorname{EI}(0))$ using 1 percent random noise added to the true $\operatorname{EI}(0)$. The inversion results from the noisy impedance data using the procedure for noise-free impedance data (that is, solving equation 5) are unstable, confirming previous research ( $\mathrm{Lu}$ and McMechan, 2004; Mallick, 2001). Inversion results for noisy impedance data using the proposed method are shown in figures 3 and 4 . In order to derive P-wave velocity and density from the AI data, $\rho=1.3+0.35 V_{P}$ is used. Results indicate that the general trend of P-wave velocity, $\mathrm{S}$-wave velocity, and density from inversion agree well with measured ones.

In order to overcome the instability of impedance inversion using equation 6, Lu and McMechan (2004) proposed the following approximation (LM approximation) for seismic data from the Blake Ridge, which is located off the southeast coast of the United States:

$$
\begin{aligned}
& \ln \left(\rho V_{S}\right) \approx \frac{\ln \left(\rho V_{P}\right)\left(1+\sin ^{2} \theta\right)-\ln (E I(\theta))}{8 k \sin ^{2} \theta}- \\
& \frac{3}{4}(0.25-k)\left(\frac{1}{a k}-\frac{k}{b}\right)
\end{aligned}
$$

where $a=8.0$ and $b=0.5$ for $k<0.25$, and $a=3.0$ and $b=3.0$ for $k>0.25$.

The inversion result for the $\mathrm{S}$-wave velocity using equation 7 is shown in figure $4 B$. Figure 4 indicates that the inversion result from the original formulation (eq. 6) works better than the LM approximation. For deeper parts of the well 

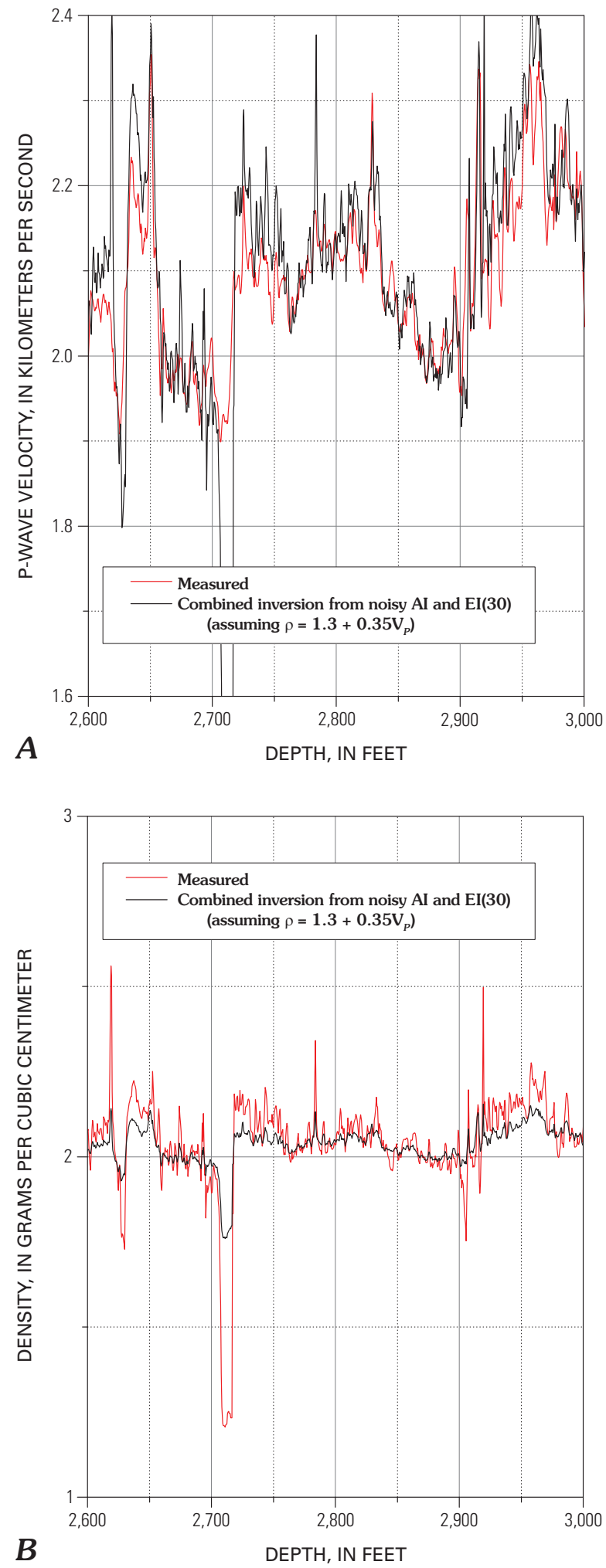

Figure 3. Example of elastic-impedance (EI) inversion for P-wave and density using noisy El data (1 percent random noise). P-wave velocities $\left(V_{\mathrm{p}}\right)$ and densities are estimated from the acoustic-impedance (Al) inversion by using $\mathrm{El}(0)$. $A$, P-wave velocity. $B$, Density. (not shown), as depth increases, the inversion result using the LM approximation deteriorates (causing underestimation), whereas the $\mathrm{S}$-wave velocity estimated from the original formulation follows the measured velocity accurately. It is not surprising that the LM approach is inferior to the present method, because the LM approximation is derived from data taken at Blake Ridge. However, a lesson from these results is that incorporating variable $k$ in the inversion scheme using the predicted $\mathrm{S}$-wave velocities eliminates the need for any approximation. Therefore, equation 6 can be successfully applied to noisy data by using the predicted S-wave velocities in the inversion scheme.

\section{Inversion by Linear Approximation}

If $k=0.25$ and the angle of incidence is small (that is, $\tan ^{2} \theta \approx \sin ^{2} \theta$ ), equation 6 can be written as (Cambois, 2000; Mallick and others, 2000)

$$
\ln \left(\rho V_{S}\right)=\frac{\left(1+\sin ^{2} \theta\right) \ln \left(\rho V_{P}\right)-\ln (E I(\theta))}{2 \sin ^{2} \theta}
$$

or

$$
\ln (E I(\theta))=\ln \left(\rho V_{P}\right)+\left[\ln \left(\rho V_{P}\right)-2 \ln \left(\rho V_{S}\right)\right] \sin ^{2} \theta
$$

There are two ways to derive $V_{s}$ through the use of this approximation. The first one is using equation $8 \mathrm{a}$ directly. The second one is using equation $8 \mathrm{~b}$ and AVO analysis. The advantage of using equation $8 \mathrm{~b}$ is that the elastic impedance can be related to the AVO parameters intercept $A$ and gradient $B$. By linear approximation of the log of EI with respect to $x=\sin ^{2} \theta$, the intercept and slope can be estimated (Mallick and others, 2000). From the estimated slope and intercept, P-wave and $\mathrm{S}$-wave impedances can be calculated.

Note that this approximation is based on the EI derived from the two-term approximation of reflection coefficient instead of the three-term approximation (Mallick, 2001). The linear approximation is possible because $k=0.25$ is assumed and the angle of incidence is less than about $25^{\circ}$ (Mallick, 2001). For unconsolidated gas-hydrate-bearing sediments, $k$ is usually less than 0.25 . Therefore, the linear approximation is not an accurate method of the impedance inversion for gashydrate-bearing sediments, as is illustrated in figure $4 A$. Most of the S-wave velocities estimated from the linear approximation of EI inversion are smaller than the measured velocities. In this example, the underestimation is mainly caused by assuming $\tan ^{2} \theta \approx \sin ^{2} \theta$, whereas the angle used here is $>25^{\circ}$. Although the accuracy of EI inversion using the linear approximation can be increased by limiting the angle of incidence to $<25^{\circ}$, models indicate that the original formulation (equation 6) works much better than the linear approximation (equation 8) for these well-log data. 

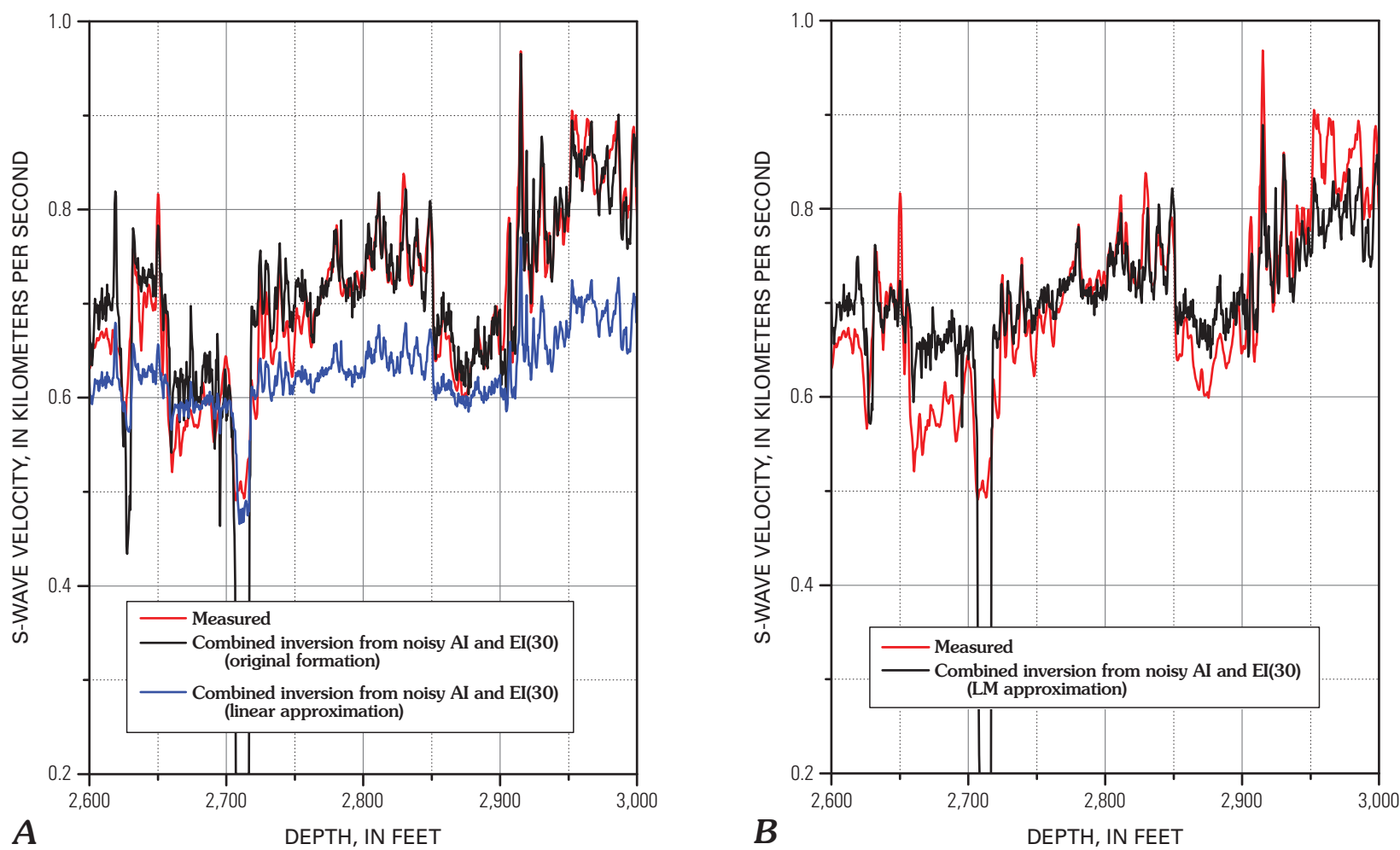

Figure 4. S-wave velocities that resulted from the elastic-impedance (El) inversion of noisy data (1 percent random noise). $A$, Estimated S-wave velocity using $k$ calculated from the predicted $S$-wave velocity and the exact El equation (that is, equation 6 ). $B$, Estimated S-wave velocity using $k$ calculated from the predicted S-wave velocity and the approximate El equation (LM approximation) of Lu and McMechan (2004). Al, acoustic impedance.

\section{AVO Inversion}

Estimating elastic parameters from the AVO analysis is a two-step process:

1. Estimate $\mathrm{P}$ - and $\mathrm{S}$-wave reflection coefficients $\left(R_{P P}\right.$ and $\left.R_{S S}\right)$ from the AVO parameters intercept $A$ and gradient $B$.

2. Estimate velocities from the reflection coefficients.

\section{Shear-Reflection Coefficient from AVO}

The three-term P-wave reflection coefficient is given by Aki and Richards (1980) as

$$
R_{P P}(\theta)=A+B \sin ^{2} \theta+C \sin ^{2} \theta \tan ^{2} \theta
$$

where

$$
A=\frac{1}{2}\left(\frac{\Delta V_{P}}{V_{P}}+\frac{\Delta \rho}{\rho}\right)=R_{P P}
$$

$$
B=\frac{1}{2} \frac{\Delta V_{P}}{V_{P}}-2\left(\frac{V_{S}}{V_{P}}\right)^{2}\left(2 \frac{\Delta V_{S}}{V_{S}}+\frac{\Delta \rho}{\rho}\right)
$$

and

$$
C=\frac{\Delta V_{P}}{2 V_{P}}
$$

The shear-wave reflection coefficient is given by

$$
R_{S S}=\frac{1}{2}\left(\frac{\Delta V_{S}}{V_{S}}+\frac{\Delta \rho}{\rho}\right)
$$

If the relationship between P-wave velocity and density given by Gardner and others (1974) is used in equation 9, it can be shown that

$$
\frac{\Delta \rho}{\rho} \approx \frac{1}{4} \frac{\Delta V_{P}}{V_{P}}=\frac{2}{5} R_{P P}=\frac{2}{5} \mathrm{~A}
$$

Then, from equations 9 through 11 , 


$$
R_{S S}=\frac{A(1+\Delta \sigma / 5)-B}{2(1+\Delta \sigma)}
$$

where $\Delta \sigma=4 \mathrm{k}-1$. If $\Delta \sigma=0$ or $\left(V_{S} / V_{P}\right)=0.5$, then equation 12 becomes (Swan, 1993; Mallick and others, 2000)

$$
R_{S S}=\frac{A-B}{2}
$$

Figure 5 illustrates the shear-reflection coefficient calculated from equation 12 with $A=0.111$ and $B=-0.172$ (these coefficients are calculated directly from equation 9 , not from a least-squares fit to the AVO data). These values are calculated from an interface between a wet-sediment $\left(V_{P}=2.088 \mathrm{~km} / \mathrm{s}\right.$, $\left.V_{S}=0.710 \mathrm{~km} / \mathrm{s}, \rho=2.140 \mathrm{~g} / \mathrm{cm}^{3}\right)$ and a gas-hydrate-bearing sediment $\left(V_{P}=2.791 \mathrm{~km} / \mathrm{s}, V_{S}=1.229 \mathrm{~km} / \mathrm{s}, \rho=1.998\right.$ $\mathrm{g} / \mathrm{cm}^{3}$ ). Therefore, a true $R_{S S}$ is 0.232 . If equation 13 is used to compute the shear-wave reflection coefficient, $R_{S S}$ is about 0.140 . Because the true $\left(V_{S} / V_{P}\right)^{2}$ across the boundary is about 0.156 (or $\Delta \sigma=-0.376$ ), the $R_{S S}$ using equation 12 is about 0.22 , which is close to the true $R_{S S}$ (shown as a closed star in fig. 5). However, equation 12 is unstable for smaller values of $V_{S} / V_{P}$. Thus, equation 13 is generally used to derive the shearreflection coefficient.

\section{Shear-Wave Velocity from AVO}

Similarly to the EI-inversion approach, the P-wave impedance is derived from the AI or from the AVO parameter intercept $A$. The estimation of $\mathrm{S}$-wave velocity is as follows:

1. Use the $\rho_{i}$ from the AI inversion to compute porosity $\phi_{i}$ under the assumption of water-saturated sediments.

2. Predict S-wave velocity $\left(V_{S, i}\right)$ from $V_{P, i}$ and $\phi_{i}$ or from just $\phi_{i}$.

3. Use $V_{P, i}$ and $V_{S, i}$ to compute $k_{i}$.

4. Use $A_{i}$ and $B_{i}$ to compute $R_{S S, i}$ from equation 13, or use $A_{i}, B_{i}$, and $k_{i}$ to compute $R_{S S, i}$ from equation 12 .

5. Use smoothed $k_{i}$ and the low-frequency part of P-wave impedance $\left(L F I_{V_{P}}\right)$ to compute the low-frequency part of shear-wave impedance $\left(L F I_{V_{S}}\right)$; that is, $\quad L F I_{V_{S}}=\sqrt{k_{i}} L F I_{V_{P}}$.

6. Compute the high-frequency part of S-wave impedance by

$$
Z S_{i}=\frac{\left(1+R_{S S, i}\right)}{1-R_{S S, i}} Z S_{i-1}, i=1, N
$$

7. Add $L F I_{V_{S}}$ to the high-frequency part of S-wave impedance

$$
Z S_{i}=Z S_{i}+L F I_{V_{S, i}}
$$

8. Use the density estimated from the AI inversion to compute $V_{S, i}$ from $Z S_{i}$.

\section{AVO Parameters from Elastic Impedance}

The AVO parameters intercept $A$ and gradient $B$ are generally derived by using least-squares fitting of the AVO data. However, these parameters can also be calculated from angle stacks. The AVO parameters and elastic impedance are related in that both are derived from the two-term approximation of the reflection coefficient shown in equation 9. The relationship between the angle stack and $\operatorname{EI}(\theta)$ is shown in equation 3 . However, the following equation for EI can be derived on the basis of the linear approximation:

$$
\ln (E I(\theta)) \approx \alpha+\beta \sin ^{2} \theta
$$

where $\alpha=\ln \left(\rho V_{P}\right)$ and $\beta=\ln \left(\rho V_{P}\right)-2 \ln \left(\rho V_{S}\right)$. Comparing equation 16 to the two-term approximation of equation 9

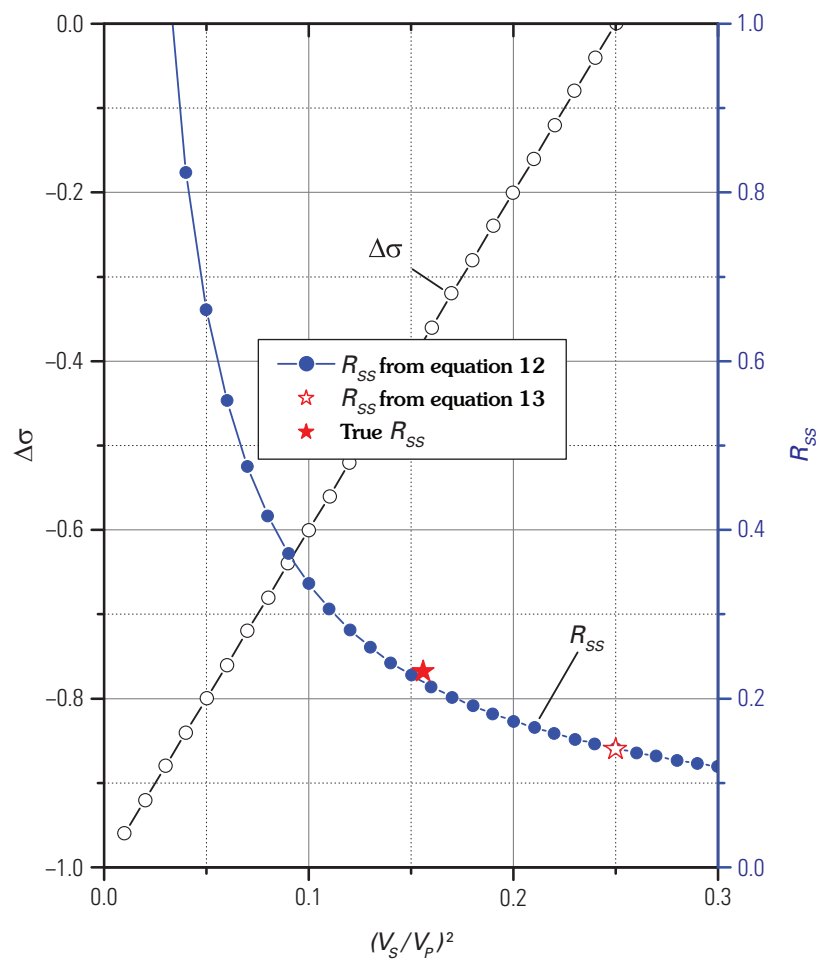

Figure 5. Relationship between reflection coefficient $\left(R_{s S}\right)$ and the squared ratio of $\mathrm{S}$-wave velocity to $\mathrm{P}$-wave velocity $\left(V_{s} / V_{p}\right)^{2}$. Parameter $\Delta \sigma\left(=4\left(V_{S} / V_{p}\right)^{2}-1\right)$ signifies the difference between the true velocity ratio and the assumed velocity ratio of 0.5 in the calculation of $R_{S S}$ 
allows the relationship between EI and AVO parameters to be derived as follows:

$$
\begin{aligned}
& A=\frac{1}{2} \frac{d \ln (E I(0))}{d t}=\frac{1}{2} \frac{d \ln (A I)}{d t} \\
& B=\frac{1}{2} \frac{d \ln (E I(\theta)) / d t}{\sin ^{2} \theta}-\frac{A}{\sin ^{2} \theta}
\end{aligned}
$$

Or, by using the angle stack given in equation 3 , the AVO parameter $B$ can be written as (Connolly, 1999)

$$
B=\frac{R_{\theta}-A}{\sin ^{2} \theta}
$$

Therefore, in practice, either AVO analysis or angle stacks can be used to estimate elastic parameters. It is noted that equations 17 and 18 assume that $k=0.25$.

Figure 6 represents estimated reflection coefficients of $\mathrm{S}$-waves from AVO intercepts and gradients derived from EI. AVO intercepts and gradients are computed by using equation 17 for the IPAD I-16 well. Figures $6 A$ and $6 B$ represent the shear-reflection coefficients estimated from intercept $A$ and gradient $B$ by using equations 12 and 13, respectively. For the depth interval between $2,710 \mathrm{ft}$ and 2,750 ft, shear-reflection coefficients calculated with equation 12 are more accurate. However, at the depth of about 2,706 ft, the estimated shearreflection coefficient is much larger than the true reflection coefficients. This discrepancy in the S-wave reflection coefficients is caused by $\Delta \sigma$ approaching -1 in the denominator in equation 12. As indicated in figure 5 , the reflection coefficient becomes very large as $\Delta \sigma$ decreases beyond about -0.6 .

In order to mitigate the problem associated with an unrealistic reflection coefficient caused by a large-magnitude value for $\Delta \sigma$, the following equation is attempted:

$$
R_{S S}=\frac{A(1+\Delta \sigma / 5)-B}{2(1+\Delta \sigma)} \quad \text { if } \Delta \sigma>-0.6
$$

$$
R_{s s} \approx \frac{A(1+\Delta \sigma / 5)-B}{2}(1-\Delta \sigma) \quad \text { if } \Delta \sigma<-0.6
$$

Figure $6 C$ represents the shear-reflection coefficient estimated with equation 19. The result indicates that equation 19 is a good practical approach for deriving shear-reflection coefficients from AVO intercepts and gradients. The result shown in figure $6 C$ indicates that, although the AVO parameters intercept $A$ and gradient $B$ are derived under the assumption of $k=0.25$, equation 19 works acceptably for the IPAD I-16 well, where the $k$ values are much smaller than 0.25 .

Figure 7 shows the estimated S-wave velocity from the AVO intercepts and gradients derived from EI. The lowfrequency part of P-wave velocity is given by

$$
L F V_{P}=1.01+3.76 d / 10,000
$$

where $L F V_{P}$ is in kilometers per second and $d$ is depth in feet. For density, Gardner and other's (1974) relationship is used.

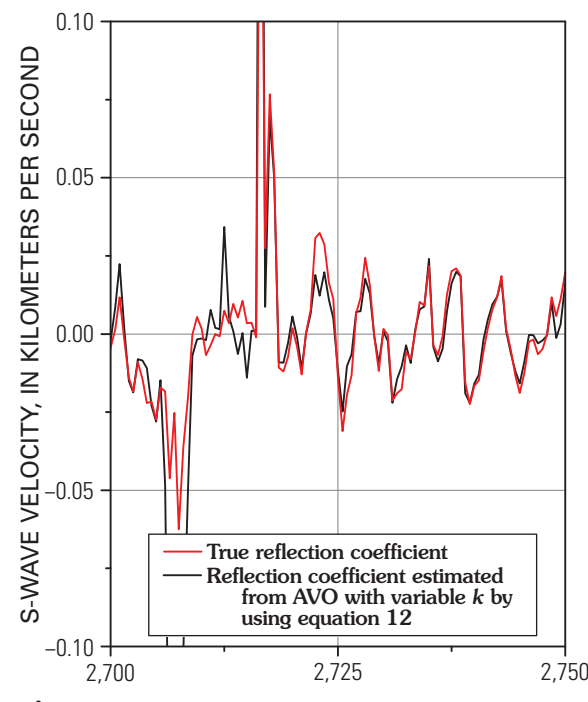

A

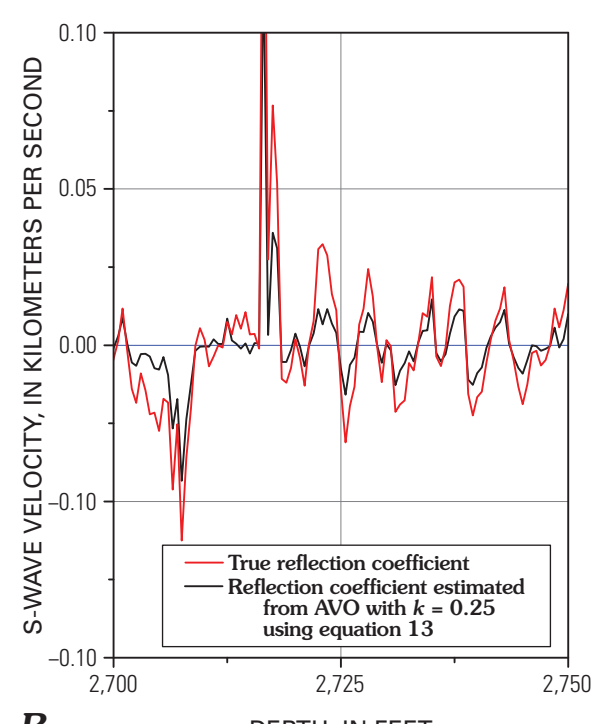

B

DEPTH, IN FEET

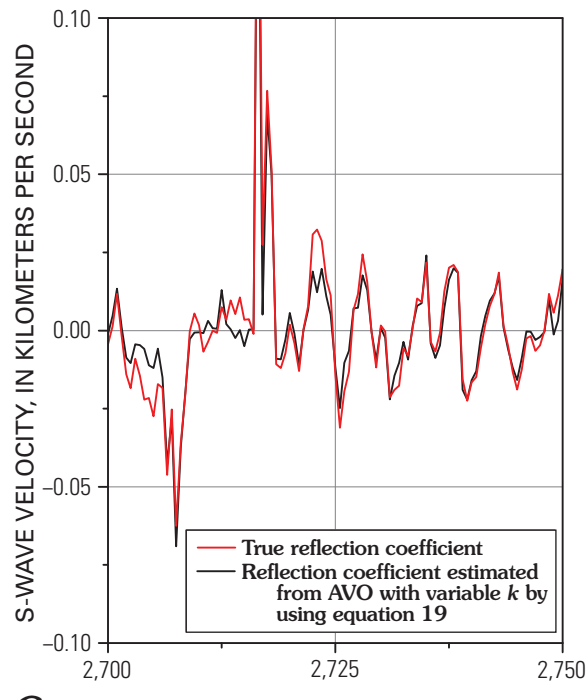

C DEPTH, IN FEET

Figure 6. The estimated shear-reflection coefficient $\left(R_{S S}\right)$ at IPAD I-16 well on the North Slope of Alaska. $A, R_{S S}$ estimated by using equation 12. $B, R_{S S}$ estimated by using conventional approach (assuming $V_{S} / V_{P}=0.5$ ). $C, R_{S S}$ estimated by using the approximation given by equation 19. AV0, amplitude-versus-offset. 
Overall, the inverted $\mathrm{S}$-wave velocity approach performs better with variable $k$ (fig. 7A) than with $k=0.25$ (fig. 7B). (It should be noted that $k=0.25$ is used only in equation 13 and the smoothed $k$ is used to derive the low-frequency part of the S-wave impedance.) The shear-reflection coefficients derived under the assumption of $k=0.25$ are less than the true reflection coefficients (fig. $6 B$ ). Consequently, the variations of inverted $\mathrm{S}$-wave velocities with respect to depth if $k=0.25$ is used are generally smaller than those of measured $\mathrm{S}$-wave velocities.

\section{Results and Analysis}

\section{El Inversion and Errors}

Model data examples indicate that the inversion of EIs with noise using equation 5 is unstable and inaccurate and support the analysis by Mallick (2001). In order to derive a stable result, a combination of estimating the S-wave velocity from $\mathrm{EI}$ and the $\mathrm{P}$-wave velocity from $\mathrm{AI}$ is investigated with good results, which confirms the analysis of $\mathrm{Lu}$ and McMechan (2004). As long as meaningful $k$ values are used, a stable inversion can be established; $k$ values can be (1) derived from an empirical formula (Lu and McMechan, 2004), (2) defined as a constant such as $k=0.25$ (Mallick and others, 2000), or (3) obtained by calculation using predicted S-wave velocities (this report). Modeling indicates that the best results are achieved by using variable values for $k$ calculated from the predicted S-wave velocity.
In order to have a stable EI inversion, the P-wave impedance is calculated from the angle stack at $0^{\circ}$, and the $\mathrm{S}$-wave velocities or impedances are calculated from equation 6 . The $\mathrm{S}$-wave velocity error associated with an error in EI can also be calculated from equation 6 . Assuming that there are no errors in the P-wave velocity and density and that the only error is in EI, then the error in EI can be written as

$$
\begin{gathered}
E I \Rightarrow E I+\Delta E I= \\
E I(1+\Delta E I / E I)=E I(1+\gamma)
\end{gathered}
$$

Likewise,

$$
V_{S} \Rightarrow V_{S}+\Delta V_{S}=V_{S}(1+\varepsilon)
$$

If equations 21 and 22 are substituted into equation 6 , the following relationship is derived:

$$
\varepsilon=\frac{\Delta V_{S}}{V_{S}}=e^{-\frac{\ln (1+\gamma)}{8 k \sin ^{2} \theta}}-1
$$

Figure 8 shows fractional errors of $V_{S}$ when a fractional error in EI is 0.1. For a given error in the EI or angle stacks, the error in the S-wave velocity increases as $k$ decreases or the degree of consolidation decreases. Therefore, more accurate EI values are required to derive accurate $S$-wave velocities for unconsolidated sediments. Also, a larger angle stack is preferred because the error decreases as the angle of incidence increases.
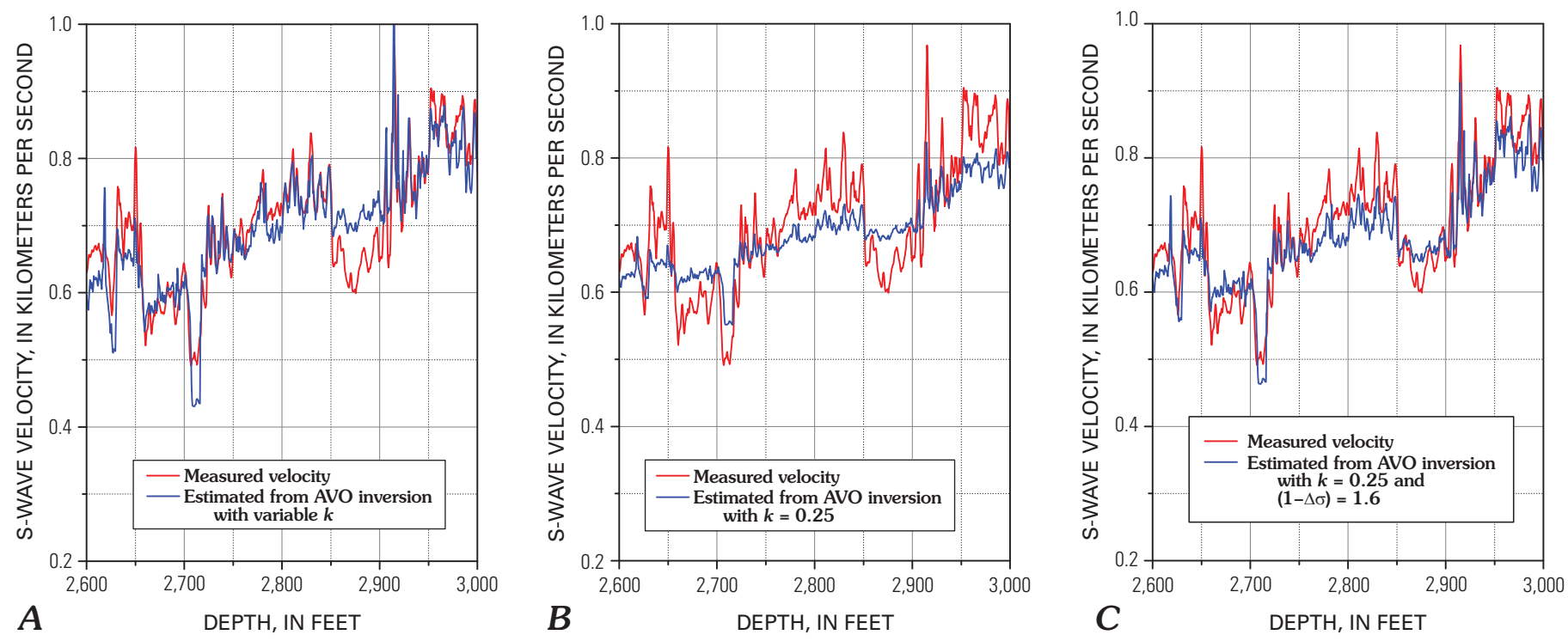

Figure 7. Estimated S-wave velocities from amplitude-versus-offset (AVO) inversion. The AVO parameters intercept $A$ and gradient $B$ are calculated by using $\mathrm{EI}(0)$ and $\mathrm{El}(30)$. $A$, S-wave velocity calculated by using the shear-reflection coefficient $\left(R_{S S}\right)$ estimated from the AVO parameters $A$ and $B$ through the use of equation 19. $B$, S-wave velocity calculated by using the $R_{S S}$ estimated from the AVO parameters $A$ and $B$ through the use of the conventional equation. $C$, S-wave velocity calculated by using the $R_{S S}$ estimated from the AV0 parameters $A$ and $B$ through the use of the conventional equation with the scaling of $(1-\Delta \sigma)=1.6$. 
Figure 9 shows the EI-inversion results for modeled data. Figure $9 A$ shows the $\mathrm{S}$-wave velocities estimated from the EI inversion when there is only 1 percent random noise in the EIs. The black line is the same as the one shown in figure $4 B$. The EI inversion using $k=0.25$ slightly overestimates $\mathrm{S}$-wave velocities, and inversion using variable $k$ values calculated from predicted $\mathrm{S}$-wave velocities is more accurate.

The effect of bulk error or bias in EIs is shown in figures $9 B$ and $9 C$. When the magnitude of the modeled EI is greater than that of the true EI, the estimated S-wave velocities are smaller than the true velocities, and EI inversion using $k=0.25$ appears to perform better than that using a variable $k$. Figure $9 C$ indicates that when the magnitude of the modeled EI is smaller than that of the true EI, the estimated $\mathrm{S}$-wave velocities are greater than the true velocities, and EI inversion using $k=0.25$ appears to perform better than that using a variable $k$.

The fractional errors in EI in figures $9 B$ and $9 C$ are about 10 percent. Figure 8 indicates that the error of S-wave velocity is about -18 percent at $k=0.25$ and -30 percent at $k=0.14$. The average $\mathrm{S}$-wave velocities are $0.700 \mathrm{~km} / \mathrm{s}, 0.595 \mathrm{~km} / \mathrm{s}$, and $0.520 \mathrm{~km} / \mathrm{s}$ for the red, blue, and black lines in figure $9 B$, respectively. These average velocities yield fractional errors of -15 percent and -26 percent for the blue and black lines, respectively, agreeing with the prediction shown in figure 8 .

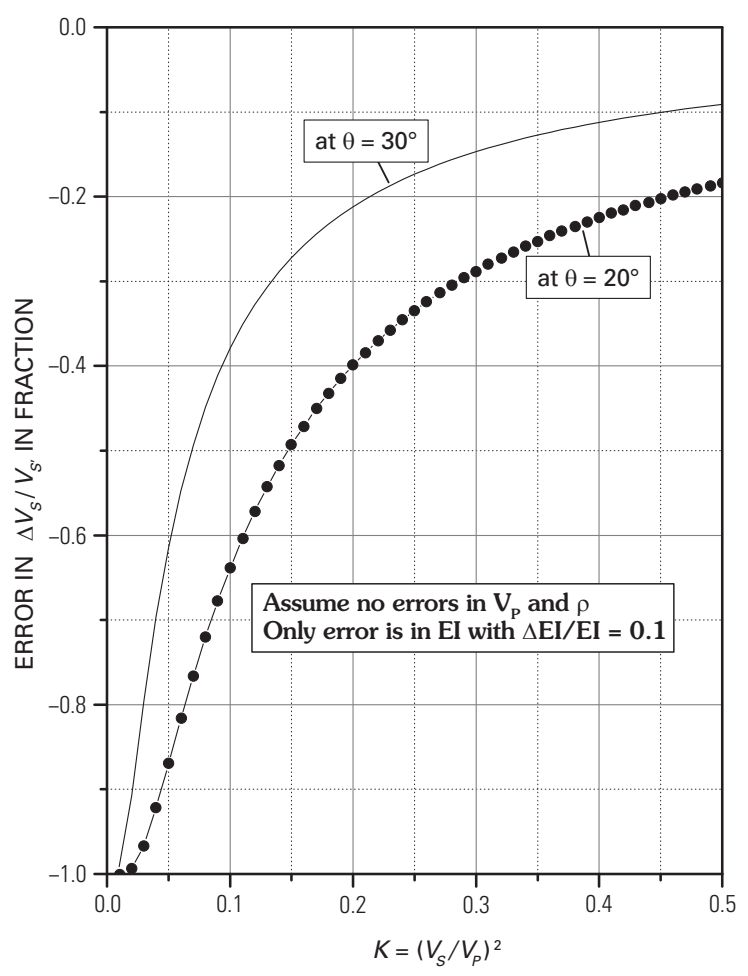

Figure 8. Errors introduced into the $\mathrm{S}$-wave velocities due to the error in elastic impedance (EI) (10 percent fractional error). $V_{p}, \mathrm{P}$-wave velocity.
The results shown in figure 9 may indicate that EI inversion with $k=0.25$ appears to work better than that using a more accurate value for $k$ based on the predicted S-wave velocities, if there are some bulk errors in EI. The appearance of better performance using $k=0.25$ is owing to the fact that the low-frequency part of S-wave velocities is better predicted, because the errors associated with bias are smaller when $k$ is larger. However, the bias error in EI can be controlled by a judicious choice of the low-frequency part of velocities or impedances. Moreover, EI inversion using variable $k$ values predicts more accurate high-frequency variation of S-wave velocity than is attained with $k=0.25$.

Examples of EI inversion with a judicious choice of the low-frequency part of S-wave velocities are shown in figure 10. In real data analysis, EI can be estimated by integrating equation 3, which yields the high-frequency part of EI. By adding the low-frequency part of EI (calculated from the predicted S-wave velocities from the low-frequency part of the $\mathrm{P}$-wave velocity) to the high-frequency part of EI, shear-wave velocities can be estimated by solving equation 6 .

Figure $10 \mathrm{~A}$ shows the $\mathrm{S}$-wave velocities estimated by equation 6 from noisy EI by using the predicted $k$, and figure $10 B$ shows those estimated by using $k=0.25$. For this model, an angle stack $R_{30}$ is calculated from equation 3 . The angle stack $R_{30}$ is added to 10 percent noise, then $R_{30}$ is integrated again to derive the high-frequency part of EI(30). Except for localized, very low $\mathrm{S}$-wave velocities due to the presence of coals, the result shown in figure $10 \mathrm{~A}$ is superior to that shown in figure $10 B$.

\section{AVO Inversion with a Scaling Factor}

Shear-reflection coefficients estimated by using equations 12 or 19 are more accurate than those derived from equation 13 , as shown in figure 6 . However, for noisy and inaccurate real data, the use of equation 13 provides more stable $S$-wave reflection coefficients than those derived by using equation 12. Commercial software packages also compute $R_{S S}$ by using equation 13. The accuracy of $\mathrm{S}$-wave velocities derived from equation 13 can be increased by the following additional step.

In real data applications, only relative values of $R_{S S}$ are known. Because of this, the $R_{S S}$ derived from AVO parameters intercept $A$ and gradient $B$ is scaled to estimate reasonable $\mathrm{S}$-wave velocities by using the AVO inversion. If $\Delta \sigma$ is small, equation 12 can be written as

$$
R_{S S} \approx R_{S S}^{*}(1-\Delta \sigma)
$$

where $R_{S S}^{*}$ is the shear-reflection coefficient derived by using equation 13. Therefore, the application of equation 12 is similar to scaling the shear-reflection coefficient derived from equation 13 , and the conventionally calculated $R_{S S}$ can be used for the inversion with appropriate scaling.

Figure $7 C$ shows the $\mathrm{S}$-wave velocities estimated from the AVO inversion by using the shear-wave reflection 


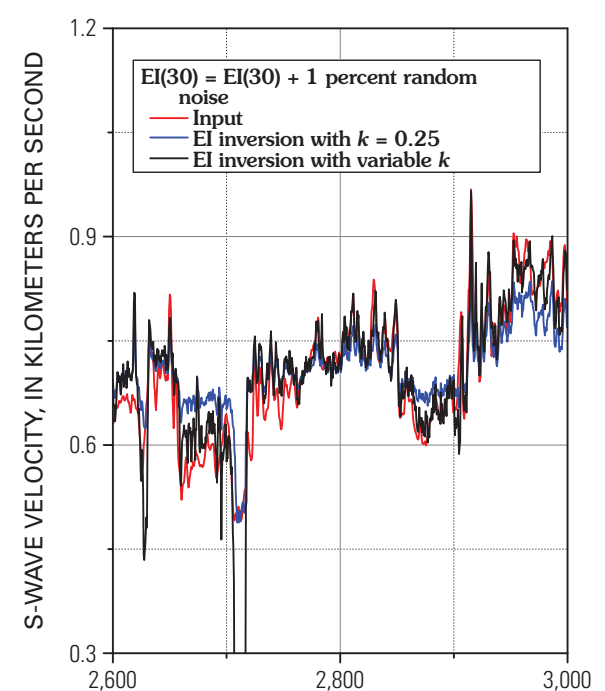

A

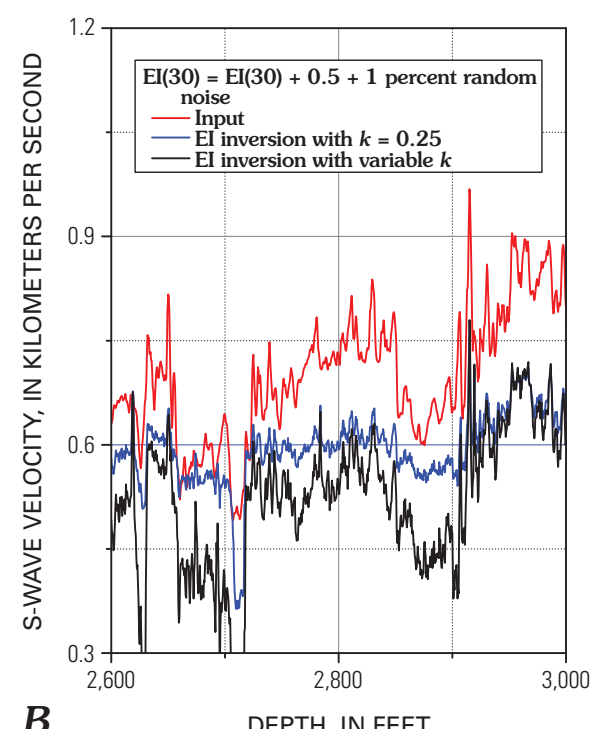

B

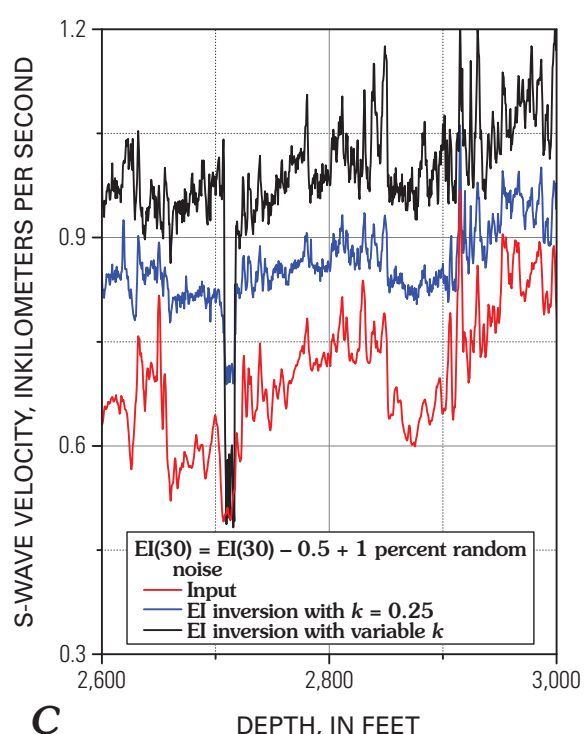

Figure 9. S-wave velocities resulting from elastic-impedance (EI) inversions for various noisy Els. $A$, From El(30) with only 1 percent random noise. $B$, From El(30) with 1 percent random noise and a fractional error of 10 percent. $C$, From El(30) with 1 percent random noise and a fractional error of -10 percent. Note that $(\mathrm{EI}(30)+0.5)$ is approximately 10 percent error in $\mathrm{EI}(30)$.

coefficients, which are calculated under the assumption that $V_{S} / V_{P}=0.5$ and corrected with a scaling factor of 1.6. The scaling factor 1.6 is calculated as follows: (1) the average $V_{S} / V_{P}$ for the measured velocities shown in figure 7 is 0.31 , and (2) on the basis of figure $5, \Delta \sigma$ for that value of $V_{S} / V_{P}$ $(0.31)$ is about -0.6 , therefore $(1-\Delta \sigma)=1.6$. A comparison of figures $7 A$ and $7 B$ makes it clear that application of equation 24 increases the accuracy of AVO inversion, particularly for unconsolidated sediments.

\section{Comparison Between El Inversion and AVO Inversion}

When using angle stacks, elastic parameters can be estimated either from the EI inversion or the AVO inversion approach. Let's assume that there is an error in the angle stack $\left(\Delta R_{\theta}\right)$ and there are no other errors. Then, the error in the $V_{S}$ from the EI inversion is given by equation 23 with

$$
\ln (1+\gamma)=2 \int \Delta R_{\theta} d z
$$

where $\gamma=\Delta E I / E I$. Similarly, the error in the $V_{S}$ using the AVO inversion with equation 18 is given in equation 23 also. Therefore, the difference between the EI inversion and AVO inversion is caused by the error in calculating the AVO gradient $B$ from the angle stack. As mentioned previously, the AVO gradient in equation 18 is derived from the linear approximation of EI. Thus, the difference between the EI inversion and
AVO inversion is the same as the difference between inversions using equation 6 and equation 8 .

Designating $V_{S}^{*}$ to be the shear-wave velocity estimated from the linear approximation of EI (equation 8a) and $V_{S}$ to be the shear-wave velocity estimated from the original equation (equation 6), then the following relationship exists between $V_{S}^{*}$ and $V_{S}$ :

$$
V_{S}^{*}=\left(V_{S}\right)^{1+\Delta \sigma} \rho^{\frac{\Delta \sigma}{2}}\left(V_{P}\right)^{\frac{-\Delta \theta}{2 \sin ^{2} \theta}}
$$

where $\Delta \theta=\tan ^{2} \theta-\sin ^{2} \theta$ and $\Delta \sigma=4 k-1$.

Figure 11 shows the relationship between $V_{S}^{*}$ and $V_{S}$ using $V_{P}=2.0 \mathrm{~km} / \mathrm{s}, \rho=2.0 \mathrm{~g} / \mathrm{cm}^{3}$, and $\theta=30^{\circ}$. The linear approximation overestimates the shear-wave velocity when $V_{S} / V_{P}$ is $<0.3$ and underestimates it when $V_{S} / V_{P}$ is $>0.3$. If the $V_{S} / V_{P}$ ratio is $>0.3$, the difference between $V_{S}$ and $V_{S}^{*}$ is small. However, as the $V_{S} / V_{P}$ ratio decreases, the difference increases. Thus, this result indicates that the linear approximation or AVO-inversion method is not a good approach for the inversion for unconsolidated sediments. Therefore, in theory, the EI-inversion method using the angle stack should perform better than the AVO-inversion approach.

Figure 10 shows practical ways of estimating elastic parameters from the angle stacks. The inversion results shown in figure 10 indicate that the optimum inversion method is EI inversion using equation 6 with variable $k$ (fig. 10A), followed by AVO inversion using equation 19 with variable $k$ (fig. 10C), followed by AVO inversion using equation 13 with a scaling factor (fig. 10D). The EI inversion with $k=0.25$ (fig. 10B) performs the worst in these examples. 

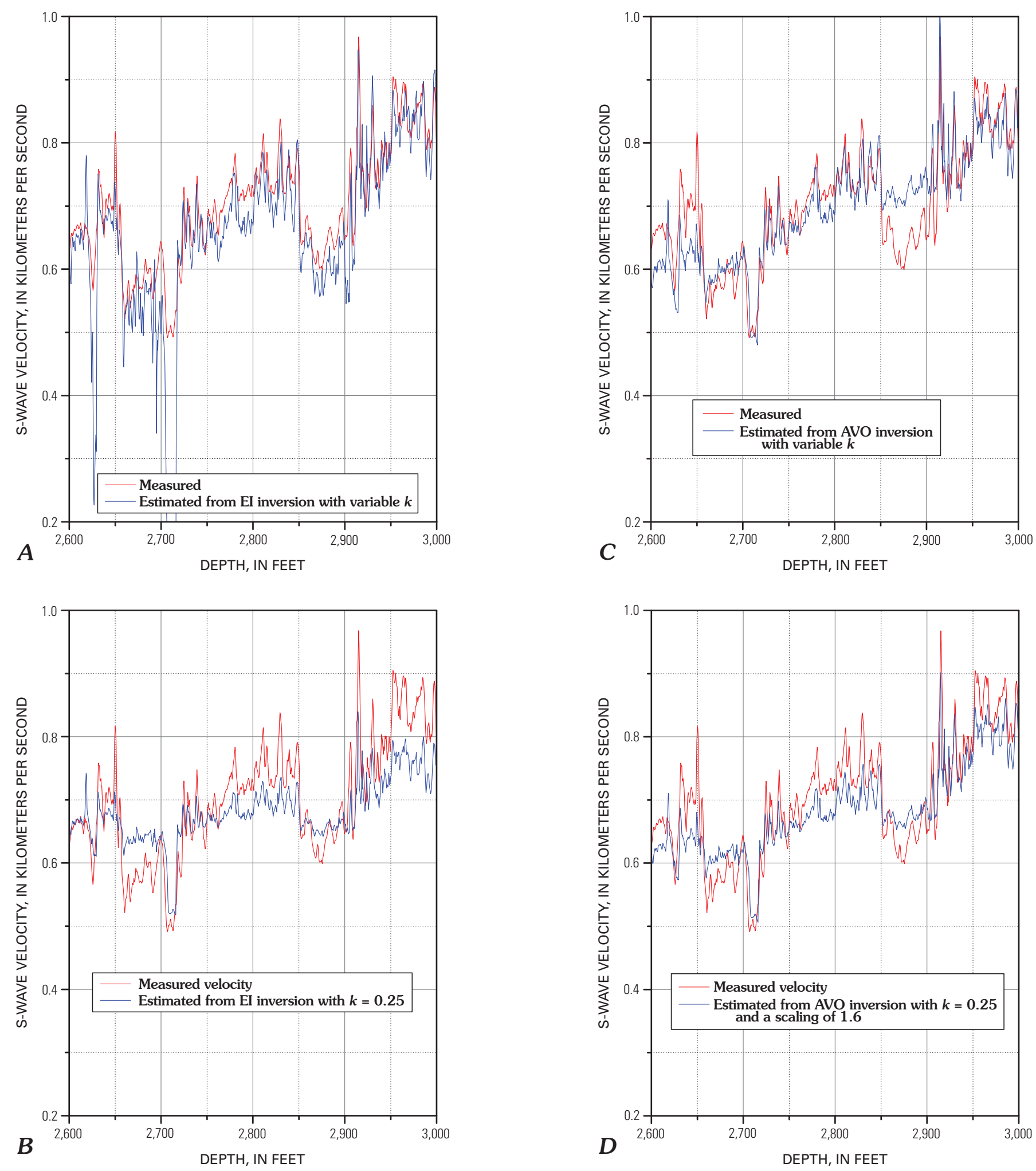

Figure 10. S-wave velocities estimated from various inversion methods by using the angle stack with 10 percent noise. $A$, Estimated from the elastic-impedance (EI) inversion with variable $k$. $B$, Estimated from the El inversion with $k=0.25$. $C$, Estimated from the amplitude-versus-offset (AVO) inversion with variable $k$. D, Estimated from the AVO inversion with $k=0.25$ and a scaling of 1.6 . 


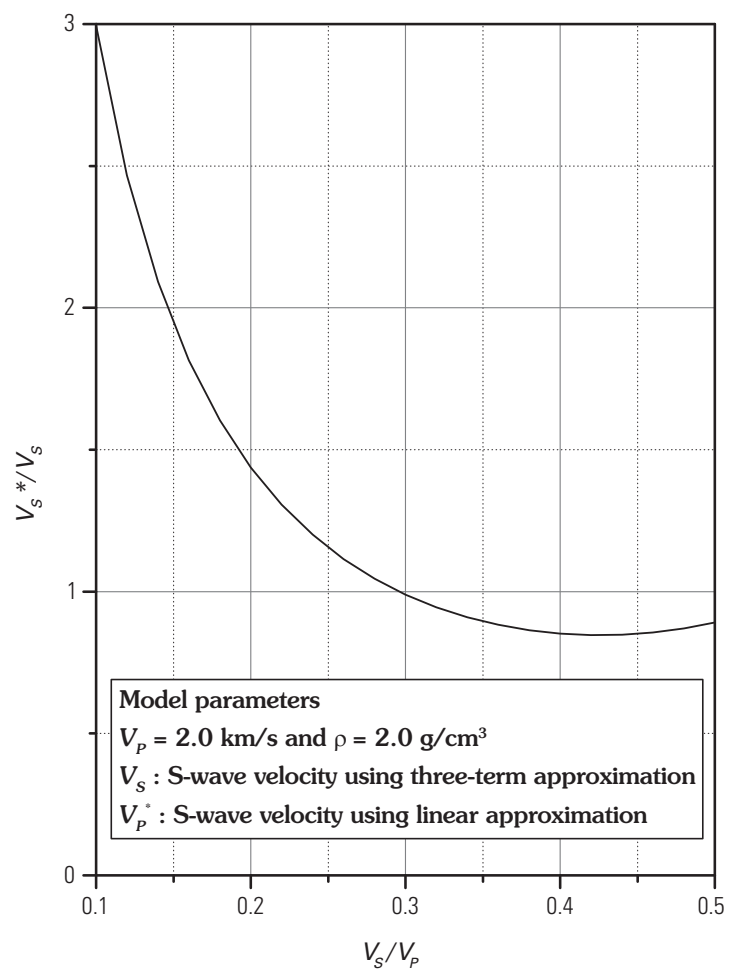

Figure 11. A comparison between shear-wave velocity $\left(V_{s}\right)$ estimated from elastic-impedance (EI) inversion by using the exact formula (equation 6 ) and shear-wave velocity $\left(V_{S}^{*}\right)$ estimated from the linear approximation (equation 8). The relationship is calculated by using $V_{P}=2 \mathrm{~km} / \mathrm{s}, \rho=2.0 \mathrm{~g} / \mathrm{cm}^{3}$, and $\theta=30^{\circ}$.

\section{Conclusion}

Inversion results using models indicate that EI inversion for noisy EIs is difficult and impractical, but reliable results can be obtained by sequentially estimating P-wave impedance and then S-wave impedance with two angle stacks. On the basis of the model examples derived from well logs, the following conclusions can be drawn:

1. EI inversion through the use of a three-term approximation of the reflection coefficient can be implemented by using a combination of estimating S-wave velocities from EI inversion with P-wave impedance estimated from AI inversion. Estimating P-wave velocity, S-wave velocity, and density by using more than three angle stacks or EIs is possible; however, even a small amount of noise in EI makes the inversion unstable and impractical.

2. A bias in EI causes EI inversion to be highly inaccurate, and the error becomes larger as the $V_{S} / V_{P}$ ratio becomes smaller; however, by adding reasonable low-frequency elastic impedances, the EI inversion provides accurate S-wave velocities.
3. Using the estimated $V_{S} / V_{P}$ ratios on the basis of predicted $\mathrm{S}$-wave velocity is a practical approach for enhancing the accuracy of EI inversion or AVO inversion using angle stacks.

4. The accuracy of AVO inversion using the data from the AVO analysis can be improved by using an appropriate scaling factor, which increases as the $V_{S} / V_{P}$ ratio decreases. This correction is important for the inversion of seismic data acquired in unconsolidated sediments.

5. Model results indicate that the optimum inversion method is the EI inversion using the angle stack with variable $k$. However, the AVO inversion using angle stacks with variable $k$ or AVO inversion with proper scaling would provide comparable results.

6. Irrespective of inversion methods, estimated velocities should be calibrated with well logs or some other independent information to better constrain the results.

\section{References Cited}

Aki, Keiiti, and Richards, P.G., 1980, Quantitative seismology theory and methods_-Volume 1: New York, W.H. Freeman and Company, $557 \mathrm{p}$.

Cambois, Guillaume, 2000, AVO inversion and elastic impedance: Society of Exploration Geophysicists, Expanded Abstracts, 70th Annual International Meeting, Calgary, Alberta, August 6-11, p. 142-145.

Collett, T.S., 2002, Energy resources potential of natural gas hydrates: American Association of Petroleum Geologists Bulletin, v. 86, p. 1971-1992.

Connolly, Patrick, 1999, Elastic impedance: The Leading Edge, v. 18, p. 438-452.

Gardner, G.H.F., Gardner, L.W., and Gregory, A.R., 1974, Formation velocity and density-The diagnostic basis for stratigraphic traps: Geophysics, v. 39, p. 770-780.

Jin, Y.K., Lee, M.W., Kim, Y., Nam, S.H., and Kim, K.J., 2003, Gas hydrate volume estimations on the south Shetland continental margin, Antarctic Peninsula: Antarctic Science, v. 15 , p. 271-282.

Lee, M.W., 2002, Modified Biot-Gassmann theory for calculating elastic velocities for unconsolidated and consolidated sediments: Marine Geophysical Researches, v. 23, p. 403-412.

Lee, M.W., 2005, Proposed moduli of dry rock and their application to predicting elastic velocities of sandstones: U.S. Geological Survey Scientific Investigations Report 20055119, 14 p. Available at http://pubs.usgs.gov/sir/2005/5119/ (last accessed March 10, 2006).

Lu, Shaoming, and McMechan, G.A., 2002, Estimation of gas hydrate and free gas saturation, concentration, and distribution from seismic data: Geophysics, v. 67, p. 582-593. 
Lu, Shaoming, and McMechan, G.A., 2004, Elastic impedance inversion of multichannel seismic data from unconsolidated sediments containing gas hydrate and free gas: Geophysics, v. 69 , p. $164-179$.

Mallick, Subhashis, 1999, Some practical aspects on implementation of prestack waveform inversion using a genetic algorithm; An example from east Texas Woodbine gas sand: Geophysics, v. 64, p. 326-336.

Mallick, Subhashis, 2001, AVO and elastic impedance: The Leading Edge, v. 20, p. 1094-1104.

Mallick, Subhashis, Huang, Xuri, Lauve, Jeffrey, and Ahmad, Riaz, 2000, Hybrid seismic inversion; A reconnaissance tool for deepwater exploration; The Leading Edge, v. 19, p. 1230-1251.

Sakai, A., 1999, Velocity analysis of vertical seismic profile (VSP) survey at JAPEX/JNOC/GSC Mallik 2L-38 gas hydrate research well, and related problems for estimating gas hydrate concentration, in Dallimore, S.R., Uchida, T., and Collett, T.S., eds., Scientific results from JAPEX/JNOC/ GSC Mallik 2L-38 gas hydrate research well, Mackenzie Delta, Northwest Territories, Canada: Geological Survey of Canada Bulletin 544, p. 323-340.

Swan, H.W., 1993, Properties of direct AVO hydrocarbon indicators, in Castagna, J.P., and Backus, M.M., eds., Offset-dependent reflectivity-Theory and practice of AVO analysis: Society of Exploration Geophysicists Investigations in Geophysics Series, v. 8, p. 78-92.

Tinivella, Umberta, and Lodolo, Emanuel, 2000, The Blake Ridge bottom-simulating reflector transect; Tomographic velocity field and theoretical model to estimate methane hydrate quantities, in Paull, C.K., and others, eds., Proceedings of the Ocean Drilling Program, Scientific results, Volume 164: College Station, Tex., Ocean Drilling Program, p. 273-281.

Whitcombe, D.N., 2002, Elastic impedance normalization: Geophysics, v. 67, p. 60-62. 